\title{
Conteúdos lúdicos, expressivos e artísticos na educação formal
}

\section{Playful, expressive and artistic content in formal education}

\author{
Jaqueline C. Castilho Moreira ${ }^{1}$ \\ Gisele Maria Schwartz ${ }^{2}$
}

\begin{abstract}
RESUMO
A prática de atividades lúdicas ou o incentivo ao fluir expressivo e artístico são propostas que permeiam a Educação, desde a Antiguidade Clássica. Atualmente, a necessidade premente de atentar para a inclusão contextualizada dessas práticas, vem sendo convalidada pelas diretrizes propostas pelos Parâmetros Curriculares tanto das disciplinas de Educação Física, como da Educação Artística. Entretanto esse espaço, ainda sutil, merece enfoque mais incisivo, por meio de estudos mais aprofundados acompanhados de práticas direcionadas que convalidem sua relevância. Assim, este estudo, de natureza qualitativa, objetivou investigar se essas variáveis estão disponíveis dentro dos conteúdos disseminados pelos professores e se possuem um espaço destinado ou não dentro da Educação formal. Para tanto, foi realizado um estudo exploratório com trinta professores voluntários, de ambos os sexos, pesquisados in loco, com consentimento livre e esclarecido, das disciplinas de Educação Física e Artística, utilizando como instrumento, para a coleta de dados, um questionário com perguntas mistas. Os dados foram analisados descritivamente, indicando que é possível notar a presença do lúdico e da arte, em ambas as disciplinas; mediando os processos de aprendizagem. Além disso, que os professores utilizam amplamente desses recursos, no entanto, nem sempre, de forma consciente e contextualizada, e que, apesar da implantação dos parâmetros curriculares desde 1998, esse espaço ainda não está consolidado.

Palavras-chave: Arte; lúdico; educação.
\end{abstract}

1. Mestra em Ciências da Motricidade/ Unesp Rio Claro - SP. Pesquisadora do Laboratório de Estudos do Lazer - LEL - DEF/I.B/Unesp Rio Claro - SP.

2. Livre Docente/Unesp, Rio Claro - SP. Coordenadora do Laboratório de Estudos do Lazer - LEL - DEF/I.B/Unesp Rio Claro - SP. 


\begin{abstract}
The practices of playing activities or the incentive to the flow of artistic expression are proposals related to education, since classical antiquity. Nowadays, the crying needs to consider the contextual inclusion of these practices have been consolidated by the proposed plans for curricular standard, either in the subjects Physical Education or Arts. However, this space, tenuous, deserves a more incisive focus, by deep studies accompanied by directed practices which consolidate its importance. So, this study, of a qualitative nature, aimed to investigate if these variables are available within the disseminated contents by the teachers, and if they have or not a specific space within formal education. So, an exploratory study was accomplished with thirty volunteer teachers, both, male and female, researched in loco, free consented, in the subjects of Physical Education and Arts, and in order to collect the data needed, it was used a questionnaire with assorted questions. The data were analyzed in a descriptive way, indicating that it is possible to find the playing activities and art, in both subjects, mediating the learning processes. Besides, it was observed that the teachers widely use these resources, however, not always in a conscious and contextual way, and in spite of the introduction of the National Curricular Parameters since 1998, this space isn't consolidated yet.
\end{abstract}

Keywords: Arts; playing activities; education.

\title{
Introdução
}

A prática de atividades lúdicas ou o incentivo ao fluir artístico são propostas que permeiam a Educação desde a Roma e a Grécia antigas. Platão, citado por Kishimoto (1992) já comentava sobre o papel da Educação como uma forma de dar ao corpo e à alma, toda a perfeição de que são capazes, além da necessidade de se aprender por meio de brincadeiras, como uma contraposição à violência e à opressão.

Aristóteles, citado por Kishimoto (1992) mencionava a necessidade de propiciar a todos os cidadãos o aprendizado das artes plásticas, dança e música; como partes integrantes da cultura intelectual do indivíduo.

Enfim, ambos os filósofos respaldavam o princípio do homo totus grego, ou seja, a suposição de que, por meio da Educação, seria possível desenvolver a totalidade das forças do homem, sem auto limitá-lo por uma estreita especialização. Essas forças, em consonância espontânea umas com as outras, ao fim, 
seriam responsáveis pela harmonização do indivíduo com seu ambiente, quer sejam objetos, natureza ou estado.

Já a Idade Média, caracterizada pela repressão e controle propiciados pelos dogmas do Cristianismo, cerceou e ocultou as diversas manifestações artísticas, por considerá-las profanas, além de empobrecer a filosofia lúdica presente nas práticas pedagógicas, por essa estar diretamente associada ao prazer.

Segundo Schwartz (1996), os ideais humanistas do Renascimento resgatam as artes clássicas e são apontados como momento efetivo de expansão do jogo educativo.

Embasado por movimentos reformistas liberais, em especial pelos princípios de Rousseau e pelas inovações educacionais difundidas por Pestalozzi, Fröebel e Montessori, o século XIX evidencia o aparecimento de novas abordagens pedagógicas, pautadas no desenvolvimento conjunto de corpo, alma e espírito, da importância da centralização no aluno em seu temperamento, talento e capacidades e na criação de recursos e metodologias. Destacam-se dentre eles: o caráter lúdico, como fator para aprendizagem e a criação de recursos sistematizados que estimulassem a expressividade das crianças.

Questiona-se até que ponto o surgimento dessas práticas educativas integradas as mobilizações filosóficas, políticas e sociais, têm gerado novos pensamentos, novas reivindicações e novas abordagens de ensino.

$\mathrm{E}$ atualmente, que tratamento vem sendo dado às atividades lúdicas nas escolas e ao "fluir artístico"? Será que propostas oriundas da academia, que se expressam nos Parâmetros Curriculares das disciplinas de Educação Artística e Educação Física, estão disseminadas e presentes na prática de docentes que atuam na rede pública paulista? Até que ponto a expressividade, o lúdico e o "fluir artístico" estão presentes nessas disciplinas? E a interdisciplinaridade, será que está permeando essas práticas?

Assim, sem a pretensão de abarcar todas as abordagens possíveis, o principal objetivo deste estudo foi averiguar se os aspectos lúdicos, expressivos e artísticos estão disponíveis dentro dos conteúdos disseminados pelos professores, e se possuem ou não um espaço destinado dentro da Educação formal.

\section{A Educação pela Arte}

A arte, ao evocar o espírito de inquietação, a necessidade natural e instintiva do homem de exaurir seu estado emocional, é também sugerida como um processo social, por constituir-se em um meio de comunicação com os 
semelhantes, afirma Ferraz (1975).

Seu papel na educação inicia uma nova forma de pensar. Para Barbosa (2002), o fundamental do significado da arte na educação é entender que ela é constituída de modos específicos de manifestação da atividade criativa dos seres humanos ao interagirem com o mundo em que vivem, ao se conhecerem e ao conhecê-lo.

Uma das ações que vem se afirmando, por sua abrangência cultural, é a "Metodologia Triangular", desenvolvida por Barbosa (2002). Para a autora, a Educação Artística deve integrar três facetas do conhecimento: o fazer artístico, a análise de obras e a história da arte, com o intuito de estimular o aluno, em vivências práticas e teóricas, trabalhos individuais e coletivos, a se tornar uma pessoa fluidora de arte, ou seja, capaz de expressar e se comunicar em artes.

Os Parâmetros Curriculares da disciplina (BRASIL, 1998) asseveram que é possível desenvolver a percepção, a imaginação, a emoção, a sensibilidade e a reflexão, ao realizar produções artísticas e interagir com diferentes materiais, procedimentos e instrumentos.

O documento ressalta, ainda, a possibilidade de se desenvolver outros conteúdos como o respeito à própria produção e à dos colegas, a compreensão e a identificação da arte das diversas culturas e épocas, a observação e a comparação das diferenças existentes nos padrões artísticos e estéticos.

Além de proporcionar, a reflexão e a discussão quanto às relações homemsociedade, o entendimento dos processos criativos dos artistas e a busca e a organização da quantidade e diversidade de materiais relacionados ao meio artístico.

\section{A Educação pelo Lúdico}

Considerado por Huizinga (1971) como um ato que expressa a liberdade de ação e proporciona prazer, o lúdico permeia tanto os jogos infantis, como as representações litúrgicas e teatrais, as atividades recreativas, as competições e os jogos de azar.

Nesta perspectiva, a conduta lúdica assemelha-se ao "fluir artístico", pois ambos colaboram com a transcendência das necessidades e preocupações cotidianas, aprimoram sensações e percepções, permitem uma imersão total no presente, aflorando novos atributos biofísicos e sociais.

Destacam-se, dentre eles, o senso de "self" e as possibilidades de se conjugar elementos não materiais, como o sonho, a criatividade, a expressividade, 
como formas catalisadoras das relações humanas pessoais com os ambientes físico e social.

Para Bomtempo (1986), a atividade lúdica envolve um elemento emocional de prazer, sem nenhum compromisso com a realidade, sendo aquela uma atividade agradável.

Marcellino (1999, p. 13) opta por abordar o lúdico não "em si mesmo", ou como forma isolada de algum brinquedo, festa ou jogo, mas "como um componente de cultura historicamente situada". O autor evidencia o lúdico como um veículo privilegiado de educação, apontando a relevância de sua prática ao aprendizado de forma geral, embora aponte a dificuldade desse reconhecimento e, até mesmo, a tentativa de furtá-lo da realidade.

Esse furto ao lúdico a que Marcellino (1990) se referiu nesse estudo, parece uma problemática ainda sem solução, já que a escola continua encarando a atitude e a conduta lúdicas, a espontaneidade, a expressividade ou o fluir artístico como algo alheio ao processo educacional.

Corrobora com essa discussão Schwartz (1996, p. 41), a qual menciona a sutileza em que as perspectivas lúdicas, expressivas e criativas ainda são abordadas. Justifica tal atitude a falta de conscientização do papel formador e educacional, ou a dificuldade de que se aceitem mudanças de valores, caso se privilegie esses enfoques, "devido à evidência produtivista de nossa cultura, que não lhe dá espaço".

Santos (2002, p. 244) assevera que o lúdico gratuito e liberto de qualquer obrigatoriedade disciplinar funcionaria como uma forma de administração do cárcere escolar, "já que a escola priva suas crianças da liberdade, espontaneidade e alegria, que caracterizam as manifestações lúdicas da infância”.

Concorda com essas afirmações Olivier (1999), ao questionar a dicotomia das antíteses: obrigação e prazer, que ocorrem no ambiente escolar. A autora denomina o mundo escolar como um local de "pré-para-ação", por procurar impor à lógica do "depois", (primeiro o dever, depois o prazer), da racionalidade, da produtividade, da competitividade, entre tantos outros valores ideológicos já prontos, os quais as crianças, não têm qualquer participação em sua construção. Para Olivier (1999, p. 19) "a especificidade da infância, que é justamente a possibilidade de vivenciar o lúdico, é ignorada em prol da disciplina, do esforço, da aquisição de responsabilidades e de outras funções".

Ao aprofundar-se na investigação a respeito das atividades lúdicas, encontra-se um amplo espectro de possibilidades. Podem ser livres de regras e servir apenas para relaxamento, também chamadas de Recreação. Podem ter regras, formalizadas de acordo com os objetivos a alcançar: competir, melhorar desempenho, aprender algo definido, conhecidas num sentido amplo como jogos, com todas as possíveis subdivisões: pré-desportivos; esportivos; espontâneos; 
criativos; jogos intelectivos; jogos em salas de aula, como as atividades criativas, a pesquisa, a discussão, a solução de problemas em grupos; jogos globais como as novelas na TV, os filmes e os inúmeros jogos virtuais.

Podem ser expressivas, contribuindo para o desenvolvimento das potencialidades e da linguagem, por meio de gestos, sons e fisionomia, ou, ainda, dramáticas, nas quais ocorrem personificações com desempenho de papéis, tendo o conflito como condição. Nesse enfoque, o aluno é estimulado a libertar sua imaginação e sua inventividade, expressando sua visão do mundo e representando diversos papéis afirma Amorin (2002).

Com base na Psicologia da Educação, acredita-se que, por meio do lúdico, a criança pode elaborar anseios e fantasias, aprender a lidar com o ganhar e o perder, aprender a administrar sua angústia, diminuir sua ansiedade diante dos conflitos, de situações complexas e confusas, além de gerar prazer, motivação e experimentação.

É possível, ainda, por intermédio da atividade lúdica, compreender a coincidência entre o espaço de aprendizagem e o espaço de jogar, além da constituição dos processos que compõem a aprendizagem.

Para Fernandez (1991), os processos são: inventariação (qual assunto, quais os temas, qual sua extensão, sua densidade, entre outros), organização (relação de conceitos) e integração- apropriação (integrar essas relações com nossos esquemas e a partir daí apropriar).

A modalidade desenvolvida e o tipo de tratamento do objeto, material, equipamento relacionado ao jogo, lançam luz sobre a cena de aprendizagem. Já os objetivos possibilitam o desenvolvimento e posterior análise das significações do aprender; a compreensão de algum desvio, a observação entre a inter-relação inteligência-desejo-corporeidade; os processos de construção do símbolo; os processos de assimilação-acomodação e seus possíveis equilíbrios, desequilíbrios e compensações; a análise das modalidades de aprendizagem; a capacidade de argumentação, a cognição e o mundo simbólico do pesquisado.

Diversos autores (BITTENCOURT; FERREIRA, 2002; SANTOS, 2006; SOARES; PORTO, 2006; PIMENTEL, 2006) asseveram que as atividades lúdicas constituem-se de atividades primárias, que trazem grandes benefícios de vários pontos de vista: físico, psíquico, intelectual, cognitivo, social, moral, afetivo, emocional, pedagógico, estético, artístico e cultural.

Embora esses benefícios estejam amplamente explicitados na literatura, não existe um consenso em relação às suas nomenclaturas e às suas definições, assim como, uma sistematização adequada, o que mereceria um posterior aprofundamento de investigação, já que não é esse o enfoque deste artigo.

Os estudos que articulam os beneficios do lúdico e a Educação Física, acrescentam a lista acima, os benefícios fisiológicos e psico-sociais, os benefí- 
cios relacionados à saúde e ao desenvolvimento motor; à formação do caráter, à tolerância, à cooperação, ao senso social; ao rendimento acadêmico; ao desenvolvimento de funções mentais como a atenção, a memória, o raciocínio e ao desenvolvimento da linguagem em suas diversas possibilidades (MIRANDA, 2002; GOMEZ, 2001; ESTRADA, 2001).

Expande as discussões, Lorenzetto (2001), ao relatar que, o comportamento desencadeado pelas atividades lúdicas é também uma das formas de se estimular a expressividade.

Pensamento que é corroborado por Schwartz (1999), a qual traça algumas relações entre a expressividade, o lúdico e a arte, ao comentar que a arte e o jogo possuem uma carga afetivo-emocional. Essa carga é capaz de interferir positivamente nos indivíduos, provocando uma transformação em seu modo de pensar e agir, ao canalizar sentimentos e emoções que resgatam o que lhes era indiferente e reconhecendo e reconstruindo novas realidades.

Por esse viés, entendendo expressividade como uma linguagem imediata, "uma espécie de estilo pessoal de cada indivíduo, manifestado por meio de seus movimentos, posições e atitudes" (STOKOE, 1987, p. 17), percebe-se uma interface viável entre o lúdico, a expressividade, a arte e a educação, motivando o interesse deste estudo.

\section{Metodologia}

Este estudo tem uma natureza qualitativa e foi desenvolvido por meio de uma pesquisa exploratória, realizada entre 2004 e 2005, para se investigar a problemática apontada.

Foram sujeitos desta pesquisa trinta professores de ambos os sexos, pesquisados in loco, com consentimento livre e esclarecido, com faixa etária entre vinte e cinquenta anos. Dentre eles, dezesseis eram professores que ministravam a disciplina de Educação Artística nas cidades de Ribeirão Preto, Santa Rosa de Viterbo, São Paulo e Jaboticabal e que estavam na rede estadual entre um a 21 anos, trabalhando, principalmente, no Ensino Fundamental.

Os outros quatorze participantes ministravam aulas de Educação Física, nas cidades de Ribeirão Preto, São José dos Campos, Rio Claro e Araraquara, tanto na rede estadual como em escolas particulares, entre um ano e meio a onze anos, trabalhando, principalmente, no Ensino Fundamental.

$\mathrm{O}$ instrumento utilizado foi um questionário único para ambas as disciplinas (ANEXO 1, p. 16), com perguntas abertas e fechadas, que além de 
dados gerais (como idade, sexo, escolaridade, características socioeconômica dos pesquisados), enfocava a disciplina ministrada; a escola onde lecionavam e a cidade; tempo de docência; se trabalhavam com Ensino Fundamental e/ou com Ensino Médio; aspectos que julgavam necessários abordar numa proposta pedagógica dentro de sua área de atuação; condições de infraestrutura oferecidas pela escola; materiais, equipamentos e recursos pedagógicos utilizados; participação dos alunos nas aulas; avaliação; se acreditavam na inclusão dos alunos com necessidades especiais de aprendizados nessas classes regulares; se utilizavam técnicas de educação motora e a opinião sobre a possibilidade da interdisciplinaridade entre Educação Física e Artística.

A amostra foi aleatória, sendo que a aplicação do instrumento se deu de forma individual, e com o aceite de participação voluntária da pesquisa.

\section{Resultados}

Os resultados foram analisados de forma descritiva, evidenciando o espaço em que a expressividade, o lúdico e o "fluir artístico" ocupavam na educação formal. Optou-se por salientar os aspectos que os professores de ambas as disciplinas acreditavam necessários abordar numa proposta pedagógica, para investigar se os próprios professores levavam em consideração o objeto desse estudo.

Para os professores de Educação Artística, os aspectos necessários numa proposta pedagógica são: o conhecimento - de artes plásticas, dança, teatro e música (42\%); a prática - o "fazer" artístico (21\%), principalmente, seguidos de discussão e reflexão (17\%); o "fluir artístico" (8\%) e atividades lúdicas e brincadeiras; os aspectos sociais e inclusão, a construção do processo criativo, estético, filosófico entre outros (4\%).

Já para os professores de Educação Física, os aspectos relevantes apontados numa abordagem pedagógica são: os aspectos sociais e inclusão (21\%); a prática, por meio das atividades rítmicas e coordenativas, modalidades esportivas e psicomotricidade (20\%); o conhecimento da cultura corporal do movimento e da temática da saúde (18\%); as atividades lúdicas e brincadeiras $(10 \%)$; a discussão e reflexão (8\%), seguidos de construção de outros processos, com respostas variadas $(23 \%)$.

O elemento lúdico consta nas respostas apresentadas tanto pelos professores de Educação Artística quanto pelos de Educação Física, como aspecto a ser abordado. No entanto, em função da grande quantidade de "construção de outros 
processos com respostas variadas", ocorrendo como respostas dos professores, embora apresentadas em baixos percentuais; a pesquisa indica uma pulverização nos modos de encaminhar os trabalhos, não dando conta em responder se em especial o lúdico está sendo trabalhado conscientemente, ou se apenas ocorre espontaneamente nas aulas.

Já o "fluir artístico" aparece claramente na disciplina de Educação Artística, mas não tão evidenciado na Educação Física, assim como a expressividade.

Esses dados podem ser interpretados como uma questão relativa à descentralização das propostas de cada professor em cada escola, como um atendimento à diversidade contextual regional. Mas também, podem indicar que as respostas dos professores demonstram um desnível de conhecimento quanto à conceituação do próprio termo "abordagem pedagógica".

Ao refletir sobre o assunto, Barbosa (2002) comenta que, ao se praticar o ensino e a aprendizagem da arte na escola, surgem também questões relacionadas ao processo educacional. Questões como os posicionamentos assumidos sobre os modos de encaminhar esse trabalho; a consonância com os objetivos educativos escolarizados; o atendimento às necessidades da cultura no mundo contemporâneo e, principalmente, o compromisso com o projeto, o que exige um competente trabalho docente.

Paralelamente, Crum (1993, p. 133) aborda as dificuldades da legitimação da Educação Física, afirmando que: "além da insatisfação perante os resultados e da crítica à qualidade da formação dos seus professores, a Educação Física tem também que enfrentar um sério cepticismo quanto à sua relevância social”.

Com relação à infraestrutura, materiais e equipamentos disponíveis para o desenvolvimento da expressividade, do lúdico e do "fluir artístico" foi verificado, por meio das respostas ao questionário, que os professores de Educação Artística dispõem de menos infraestrutura do que os de Educação Física. Enquanto os primeiros trabalham na própria sala de aula, sem nenhum tipo de preparo; os outros, apesar da precariedade das construções em muitas escolas, trabalham, preferencialmente, nas quadras e, eventualmente, utilizando os arredores da escola, como as praças e a rua. Neste sentido, percebe-se que existe o espaço físico, mas seu aproveitamento dependerá da proposta pedagógica dos professores, da priorização desses aspectos em suas abordagens e criatividade.

Quanto aos recursos pedagógicos e materiais utilizados, os professores trabalham com a diversidade, concordando entre si quanto ao uso de materiais específicos das suas disciplinas, disponíveis na escola. Mas também, não descartam o uso da tecnologia representada pelo vídeo, computador, internet, retroprojetor, materiais e equipamentos alternativos, confeccionados pelos próprios alunos, como maneira de suprir as carências.

A prática de atividades lúdicas, expressivas e artísticas pelos alunos foi 
recuperada das respostas dadas pelos professores, sendo que, no caso da Educação Física, foram elencados vários tipos de jogos, brinquedos e atividades recreativas; a construção de materiais alternativos pelos próprios alunos para a prática nas aulas, bem como as atividades rítmicas e danças. Já na Educação Artística, foram apontadas brincadeiras e atividades lúdicas, danças, atividades expressivas como parte das metodologias utilizadas em aula.

O lúdico está presente em ambas as aulas e, por ser uma forma prazerosa do aluno experimentar novas situações, colabora na sua compreensão e assimilação do mundo cultural e estético. Essa resposta vem ao encontro do pensamento de Ferraz e Fusari (1993), ao apontarem que a prática artística pode ser vivenciada como uma atividade lúdica, em que o "fazer" se identifica com o "brincar", e o imaginar com a experiência da linguagem, da expressividade e da representação.

Com relação à participação dos alunos em sala de aula, em ambas as disciplinas, ela é frequentemente ativa, na maior parte das vezes (44\% ativa na Educação Física e 78\% ativa nas Artes), no entanto, foi ressaltado por 45\% dos professores de Educação Física e 22\% de Educação Artística, que depende muito da relação professor-aluno e da atividade desenvolvida.

Comprova-se esse tipo de participação, por exemplo, no caso da Educação Artística, quando os alunos trazem os materiais pedidos com certa frequência; comentam entre si, na família e com o professor, sobre o reconhecimento das linguagens artísticas fora do ambiente escolar, em seu cotidiano e nas mídias; além de notarem a presença do aspecto lúdico, ao externarem sobre a diversão e o prazer que a aula proporciona: "bem que a aula de artes poderia durar o dia todo" (opinião de um aluno na fala do professor).

Na Educação Física destaca-se a fala de um professor: "a participação depende da turma... extravasam tudo, é um momento de loucura total... parece que o mundo vai acabar depois da Educação Física".

Corrobora com a questão da participação e da adesão às atividades, Bailão, Oliveira e Corbucci $(2002$, p. 2), os quais defendem a ideia de que a aula de "Educação Física é - ou deveria ser - o espaço da liberdade", em que a criança se sente a vontade para realizar atividades próprias de sua idade, revelando suas habilidades, capacidades, inteligências, competências e potencialidades numa atmosfera lúdica, recreativa e persuasiva, ou ainda Barbosa (2002), ao evidenciar que as aulas de arte constituem-se em espaços em que as crianças podem exercitar suas potencialidades perceptivas, imaginativas ou fantasiosas.

Ao serem questionados sobre a facilitação da inclusão dos alunos com necessidades educacionais especiais básicas por meio das aulas das disciplinas pesquisadas, $82 \%$ dos professores de Educação Física e $87 \%$ dos professores de Educação Artística acreditam ser possível, desenvolvendo as atividades ca- 
racterísticas de cada conteúdo, melhorando a autoestima, o senso de "self" ou a vontade de aprender. Uma das professoras de Educação Artística comentou: "Todos são capazes de produzir, mesmo sendo limitados".

Uma das maneiras de verificar se a expressividade, o lúdico e o "fluir artístico" têm espaço nas aulas de Educação Física e Artística foi investigando a questão da interdisciplinaridade, por existir várias possibilidades de intercâmbio entre as disciplinas.

A amostra, de maneira geral, é favorável à interdisciplinaridade ( $86 \%$ da Educação Física e 78\% da Educação Artística). Todos os professores de Educação Artística acreditam ser ótimo e importante trabalhar o conteúdo de artes com o de Educação Física, em função da transferência de conhecimentos, da possibilidade de trabalhos em conjunto e da complementação entre os conteúdos.

No entanto, duas professoras fizeram as seguintes ressalvas: "acho válido, desde que não se percam as especificidades" e a outra "depende dos critérios a serem usados".

Os professores de Educação Física acreditam que a interdisciplinaridade pode ser benéfica predominantemente. Mesmo respondendo favoravelmente, dois deles questionaram o pouco tempo disponível dos professores das duas áreas na escola para planejarem em conjunto e, ainda, a dificuldade de conciliação, em função do pequeno relacionamento dos envolvidos.

Dois dos professores de Educação Física não concordam. Um deles arguiu: “A grande maioria dos professores da área não realizam um trabalho básico coerente e responsável, reduzindo os conteúdos e temas que fazem parte do corpo de conhecimento da Educação Física ao simples praticar esporte. Não estão dando conta do recado com o básico... essa é a minha preocupação com novos conteúdos, de ficar algo mais superficial do que aquilo que está acontecendo".

Já outro comentou que "prefere trabalhar com a especificidade dos conteúdos da Educação Física, que são muitos".

Divergindo dos anteriores, é importante registrar a opinião de um professor de Educação Física, que trabalha com recreação, eventos e dança: "Tem tudo a ver. Tem trabalho corporal, desenvolvimento motor e expressividade. Acho que os que estão preocupados com as especificidades de conteúdo, tanto de arte quando de atividade física, tem medo de perder espaço de suas disciplinas na escola".

Vale ressaltar que a Lei de Diretrizes e Bases da Educação Nacional (LDB 9394/96), vigente, estabelece a Educação Física como cultura corporal do movimento e que a Arte deixou de ser uma atividade, para tornar-se um conhecimento, com conteúdos próprios e específicos. 


\section{Considerações finais}

A partir dos depoimentos dos professores de ambas as disciplinas, nesta amostra, observou-se uma falta de coesão quanto aos aspectos que acreditavam necessários a serem abordados numa proposta pedagógica, o que evidencia a necessidade de um aprofundamento e análise na investigação de como esses professores realizam suas propostas pedagógicas, quais critérios, quais enfoques, quem participa e os questionamentos com relação à idealização e a prática efetiva. Isso sugere a necessidade de um repensar sobre os conteúdos e ações, no que tange ao espaço reservado ao elemento lúdico e ao "fluir artístico" de forma consciente.

Em função das respostas dos professores pesquisados, foi apontada a situação precária em que ministram suas aulas, em termos de local, materiais e equipamentos. No entanto, apesar dessas condições adversas, não há grandes empecilhos para aplicação do lúdico e do "fluir artístico".

Nesse estudo, verificou-se que, apesar de presentes nas falas dos pesquisados, os professores nem sempre utilizam o "fluir artístico", a expressividade e o lúdico, como mediadores contextualizados em suas práticas, o que os coloca numa tênue divisa entre: o emprego consciente de saberes e o "passar o tempo" (palavras de um aluno), o que acaba por desvalorizar as disciplinas dentro da grade escolar.

É nítida a necessidade de se manter a especificidade de conteúdos, de aprofundar-se nas técnicas de mediação dos processos de aprendizagem e de contextualizar e convalidar o espaço do lúdico, da expressividade e do "fluir artístico" na escola, até mesmo por uma questão de construção efetiva da identidade de cada uma das disciplinas; assim como, de seu posicionamento político dentro do contexto escolar, evitando que, mais uma vez, sejam abolidas da grade de ensino.

As possibilidades de interface entre a Educação Física e a Artística, no que tange ao espaço do lúdico, da expressividade e do "fluir artístico", podem colaborar de forma sinérgica como reivindicações de ordem física: espaço, equipamento, bastante salutar para as disciplinas. Como também podem tornar seus conteúdos bastante estimulantes, não só para os alunos como para os próprios professores, para a escola e para a comunidade, o que merece outras reflexões, no sentido de ampliar as discussões e promover novos debates, capazes de implementar essas intersecções. 


\section{REFERÊNCIAS}

AMORIN, J. S. Uma janela para todos: as novas mídias informatizadas na escola aberta às diferenças. 226 f. Dissertação (Mestrado em Educação) - Faculdade de Educação, Universidade Estadual de Campinas, Campinas, 2003.

BAILÃO, M.; OLIVEIRA, R. J.; CORBUCCI, P. R. Educação Física inclusiva e as múltiplas inteligências. Revista digital, Buenos Aires, año 8, n. 49, jun. 2002. Disponível em: <http://www.efdeportes.com/efd49/efil.htm>. Acesso em: 29/7/2008.

BARBOSA, A. M. T. B. Inquietações e mudanças no ensino da arte. São Paulo: Cortez, 2002.

BITTENCOURT, R. G.; FERREIRA, M. D. M. A importância do lúdico na alfabetização. 36 f. Monografia (Conclusão do Curso de Pedagogia) - Centro de Ciências Humanas e Educação, Universidade da Amazônia, Manaus, 2002.

BOMTEMPO, E.; HUSSEIN, C. L.; ZAMBERLAN, M. A.T. (Coord.). Psicologia do brinquedo: aspectos teóricos e metodológicos. São Paulo: Nova Stella/Edusp, 1986.

BRASIL. Ministério da Educação e do Desporto. Secretaria da Educação Fundamental. Parâmetros Curriculares Nacionais: $5^{\mathrm{a}}$ a $8^{\mathrm{a}}$ séries do Ensino Fundamental - Introdução aos Parâmetros Curriculares. Educação Física e Educação Artística. Brasília: MEC/SEF, 1998.

CRUM, B. A crise de identidade da Educação física. Ensinar ou não ser, eis a questão. In: Boletim Sociedade Portuguesa de Educação Física (SPEF), n. 7/8. Inverno/ Primavera, p. 133-148, 1993.

ESTRADA, P. R. Actividad física y salud mental. Revista Digital, Buenos Aires, año 7, n. 40, set. 2001. Disponível em: < http://www.efdeportes.com/efd40/smental.htm >. Acesso em: 29/7/2008.

FERNÁNDEZ, A. A inteligência aprisionada - abordagem psicopedagógica clínica da criança e sua família. Porto Alegre: Artes Médicas, 1991.

FERRAZ, G. Retrospectiva: figuras, raízes e problemas da arte contemporânea. São Paulo: Cultrix/Edusp, 1975.

FERRÁZ, M. H.; FUSARI, M. F. R. Metodologia do ensino da arte. São Paulo: Cortez, 1993.

GOMEZ, H. El juego y juguete, elementos trascendentales en el acto lúdico del hombre. Revista Digital, Buenos Aires, año 7, n. 40, set. 2001. Disponível em: <http://www. efdeportes.com/efd40/juego.htm>. Acesso em: 29/7/2008. 
HUIZINGA, J. Homo Ludens: o jogo como elemento da cultura. São Paulo: Perspectiva/ Edusp, 1971.

KISHIMOTO, T. M. O jogo, a criança e a educação. 254 f. Tese (Livre Docência em Educação) - Faculdade de Educação, Universidade de São Paulo, São Paulo, 1992.

LORENZETTO, L. A. A coragem de brincar. Revista Motriz, v. 17, n. 1, p. 53-56, jan/jun. 2001.

MARCELLINO, N. C. Lúdico e Lazer. In: Educação Física. Ijuí: Unijuí, 1999, p. 11-14. . (Org). Lúdico, Educação e . Pedagogia da Animação. Campinas: Papirus, 1990.

MIRANDA, N. 210 Jogos infantis. Belo Horizonte: Itatiaia, 2002.

OLIVIER, G. G. F. Lúdico e escola: entre a obrigação e o prazer. In: MARCELLINO, N. C. (Org). Lúdico, Educação e Educação Física. Ijuí: Unijuí, 1999, p. 15-24.

PIMENTEL, S. C. O especial dos jogos e brincadeiras no atendimento às diferenças. Temática: Educação, arte e ludicidade. Revista FAEBA: Educação e contemporaneidade, Salvador, v. 15, n. 25, p. 147-156, jan./jun., 2006.

SANTOS JR., M. F. Da liberdade da infância ao cárcere escolar. In: CONGRESSO CIENTÍFICO LATINO AMERICANO DA FIEOP-UNIMEP, 2.; e SIMPÓSIO CIENTÍFICO CULTURAL EM EDUCAÇÃO FÍSICA E ESPORTES - BRASIL/ CUBA, 2002, Piracicaba: Coletâneas... Piracicaba: Fieop-Unimep, 2002, p. 244.

SANTOS, M. J. E. Ludicidade e educação emocional na escola: limites e possibilidades. Temática: Educação, arte e ludicidade. Revista FAEBA: Educação e contemporaneidade, Salvador, v. 15, n. 25, p. 27-42, jan./jun., 2006.

SCHWARTZ, G. M. A Arte no contexto da Educação Física. Revista Motriz, v. 5, n. 1, p. 49-51, 1999.

. As atividades lúdicas no contexto da Educação Física Escolar. 75 f. Tese (Doutorado em Psicologia) - Instituto de Psicologia, Universidade de São Paulo, São Paulo, 1996.

SOARES, I. M. F.; PORTO, B. S. Se der a gente brinca: crenças das professoras sobre ludicidade e atividades lúdicas. Temática: Educação, arte e ludicidade. Revista FAEBA: Educação e contemporaneidade, Salvador, v. 15, n. 25, p. 55-78, jan./jun., 2006.

STOKOE, P., HARF, R. Expressão corporal na pré-escola. São Paulo: Summus, 1987. 


\section{ANEXO 1: Questionário realizado com Docentes}

1. DADOS GERAIS:

a) idade:

b) sexo: ( ) masculino ( ) feminino

c) Formação acadêmica:

2. DISCIPLINA MINISTRADA:

( ) Educação Artística ( ) Educação Física

3. ONDE LECIONA ATUALMENTE? MENCIONE O NOME DA ESCOLA E A CIDADE:

4. QUANTO TEMPO TRABALHA COMO DOCENTE?

5. TRABALHA COM:

( ) Ensino fundamental ( ) Ensino médio ( ) Ambos

6. QUAIS OS ASPECTOS QUE JULGAM NECESSÁRIOS SEREMABORDADOS NUMA PROPOSTA PEDAGÓGICA DENTRO DE SUA ÁREA DE ATUAÇÃO?

7. QUAIS AS CONDIÇÕES DE INFRAESTRUTURA OFERECIDAS PELA ESCOLA?

8. QUAIS OS MATERIAIS, OS EQUIPAMENTOS E OS RECURSOS PEDAGÓGICOS QUE SÃO UTILIZADOS EM SUAS AULAS?

9. COMO É A PARTICIPAÇÃO DOS ALUNOS:
( ) Ativa
( ) Passiva
( ) Depende de 
MOREIRA, J. C. C.; SCHWARTZ, G. M. Conteúdos lúdicos, expressivos ...

10) COMO É FEITA A AVALIAÇÃO?

11) ACREDITA NA INCLUSÃO DOS ALUNOS COM NECESSIDADES ESPECIAIS DE APRENDIZAGEM NAS CLASSES REGULARES? COMENTE:

12) UTILIZA TÉCNICAS DE EDUCAÇÃO MOTORA? COMENTE:

13) QUALA SUA OPINIÃO SOBRE A POSSIBILIDADE DE TRABALHAR O CONTEÚDO DE ARTES COM O DE EDUCAÇÃO FÍSICA? COMENTE SUAS RAZÕES: 